\title{
Post-millennial trends of socioeconomic inequalities in chronic illness among adults in Germany
}

Jens Hoebel ${ }^{1 *} \mathbb{C}$, Benjamin Kuntz ${ }^{1}$, Irene Moor ${ }^{2}$, Lars Eric Kroll ${ }^{1}$ and Thomas Lampert ${ }^{1}$

\begin{abstract}
Objective: Time trends in health inequalities have scarcely been studied in Germany as only few national data have been available. In this paper, we explore trends in socioeconomic inequalities in the prevalence of chronic illness using Germany-wide data from four cross-sectional health surveys conducted between 2003 and 2012 ( $n=54,197$; ages 25-69 years). We thereby expand a prior analysis on post-millennial inequality trends in behavioural risk factors by turning the focus to chronic illness as the outcome measure. The regression-based slope index of inequality (SII) and relative index of inequality (RII) were calculated to estimate the extent of absolute and relative socioeconomic inequalities in chronic illness, respectively.

Results: The results for men revealed a significant increase in the extent of socioeconomic inequalities in chronic illness between 2003 and 2012 on both the absolute and relative scales $\left(\mathrm{SI}_{2003}=0.06, \mathrm{SI}_{2012}=0.17, p\right.$-trend $=0.013$; $\mathrm{RI}_{2003}=1.18, \mathrm{RI}_{2012}=1.57, p$-trend $\left.=0.013\right)$. In women, similar increases in socioeconomic inequalities in chronic illness were found $\left(\mathrm{SII}_{2003}=0.05, \mathrm{SI}_{2012}=0.14, p\right.$-trend $=0.022 ; \mathrm{RI}_{2003}=1.14, \mathrm{RI}_{2012}=1.40, p$-trend $\left.=0.021\right)$. Whereas in men this trend was driven by an increasing prevalence of chronic illness in the low socioeconomic group, the trend in women was predominantly the result of a declining prevalence in the high socioeconomic group.
\end{abstract}

Keywords: Social determinants of health, Chronic conditions, Health inequalities, Socioeconomic inequalities in health, Health monitoring

\section{Introduction}

Over the past decades, public health research has paid increasing attention to the social determinants of health [1-4]. A wide range of studies consistently show that people with lower socioeconomic status (SES) experience poorer health, have increased risk of chronic illness, and die at younger ages than those with higher SES [5-9]. In recent years, a growing number of studies from many European countries have investigated how the health gap between lower and higher SES groups has developed over time, that is, whether the gap has largely remained unchanged over decades or whether it narrowed or

\footnotetext{
*Correspondence: j.hoebel@rki.de

${ }^{1}$ Unit of Social Determinants of Health, Department of Epidemiology and Health Monitoring, Robert Koch Institute, General-Pape-Straße 62-66, 12101 Berlin, Germany

Full list of author information is available at the end of the article
}

widened during some periods [10-17]. In Germany, however, trends in health inequalities have been investigated less often as there were relatively few national data containing both SES and health variables, to establish time series of some length [18-20].

In the early 2000s, Germany started to establish a national health monitoring system administered by the Robert Koch Institute (RKI) on behalf of the German Federal Ministry of Health [21, 22]. Among different health interview and examination surveys, repeated cross-sectional health interview surveys are carried out among the general adult population of Germany to provide data on time trends in population health [23-25]. In two previously published articles, we reported results from a time-trend analysis based on these data. Our findings indicated that social inequalities in tobacco smoking and leisure-time physical inactivity have persisted and even widened among adults in Germany since the 
early 2000s [26, 27]. In the present paper, we expand this analysis by turning the focus from behavioural risk factors to chronic illness as a health outcome indicator. We explore trends in socioeconomic inequalities in chronic illness among the general adult population of Germany using the same survey data and analytical methods as in the two previously published articles.

\section{Main text \\ Methods}

The data used in the analysis were derived from four cross-sectional telephone health surveys among adults living in private households across Germany [22, 23]. The first Germany-wide telephone health survey was conducted in 2003 and was continued in the 'German Health Update' (GEDA) surveys in 2009, 2010, and 2012 [23]. Each survey was based on a two-stage sampling procedure. In the first stage, random samples of telephone numbers were generated using random digit dialling. In the second stage, one adult member of each contacted household was randomly selected for interview. Sample sizes of participants aged 25-69 years were $n=6890$ in 2003, $\mathrm{n}=16,418$ in 2009, $\mathrm{n}=17,145$ in 2010, and $\mathrm{n}=13,744$ in 2012 . Data were collected using standardised computer-assisted telephone interviewing in each of the surveys. Further information on the survey design, contents, response rates, and sample characteristics can be found in the study descriptions $[23,28]$ and in the two previously published articles presenting time-trend analyses based on these data [26, 27].

In each of the four surveys, chronic illness was assessed by asking all participants the following yes/no question, "Do you have one or more long-lasting chronic illnesses? Chronic illnesses are long-standing diseases requiring constant treatment and monitoring, for example, diabetes or heart diseases". Participants' SES was determined using a composite index developed for all surveys conducted by the Robert Koch Institute as components of the German national health monitoring system. The index is an additive index based on information about participants' educational attainment (school and professional education), occupational position, and net equivalent income. Details on the index and methods used in its construction are described elsewhere [29, 30].

In the statistical analysis, we calculated prevalence rates for chronic illness by SES and sex. We computed predictive margins [31] from logistic regression models to predict age-standardised prevalence rates according to SES, sex, and survey year. Changes in the extent of socioeconomic inequalities in chronic illness were examined by calculating the slope index of inequality (SII) and relative index of inequality (RII) for each survey year $[32,33]$. The SII and RII are regression-based summary measures that take into account the entire distribution of a socioeconomic variable as well as the size of socioeconomic groups [33, 34]. The indices complement each other in that the SII quantifies the magnitude of absolute health inequality whereas the RII indicates the magnitude of relative health inequality. Whereas the SII can be interpreted as the age-adjusted prevalence difference between people with the lowest and those with the highest SES, the RII represents the age-adjusted prevalence ratio between these groups. Particularly in time-trend analysis, selective use of exclusively absolute or relative measures of health inequality can lead to biased assessment of increasing or decreasing health inequality over time, which is why it is recommended to consider both measures whenever possible $[34,35]$.

We used generalised linear regression models for binomial data, with an identity link function (linear probability model) to compute the SII and a logarithmic link function (log-binomial model) to calculate the RII. Changes in the SII and RII over time were analysed by adding an interaction term between SES and survey year to the models while adjusting for age, age $\times$ year, and the main effects of SES and year. Weighting factors were used to account for unequal sampling probabilities and to adjust the distribution of each sample by sex, age, education, and region to match the official population statistics for Germany. Analyses were performed using Stata 14.1 (StataCorp LP, College Station, TX, USA) survey data commands.

\section{Results}

Across the study period, the crude prevalence of chronic illness varied between 34.5 and $37.6 \%$ among men and between 40.1 and $41.5 \%$ among women. As shown in Fig. 1, chronic illness was significantly more prevalent $(p<0.001)$ in lower than in higher SES groups during each survey year and in both sexes, except for men in 2003. Among men in 2003, the crude prevalence differences by SES were not statistically significant either at the 5 or $10 \%$ level. Figure 2 shows predictive margins representing age-standardised prevalence rates for chronic illness as predicted by logistic regression. Among men, the results revealed a significant increase in the prevalence of chronic illness in the low SES group from 2003 to 2012 $(p=0.009)$; in the middle and high SES groups, the prevalence was not found to have changed significantly across this period. Among women, the prevalence of chronic illness declined in the high SES group (significant at the $10 \%$ level with $p=0.063$ ); no significant trend was found in the middle and low SES groups at either the 5 or $10 \%$ level.

Table 1 presents the summary measures of absolute and relative inequalities in chronic illness. The result 


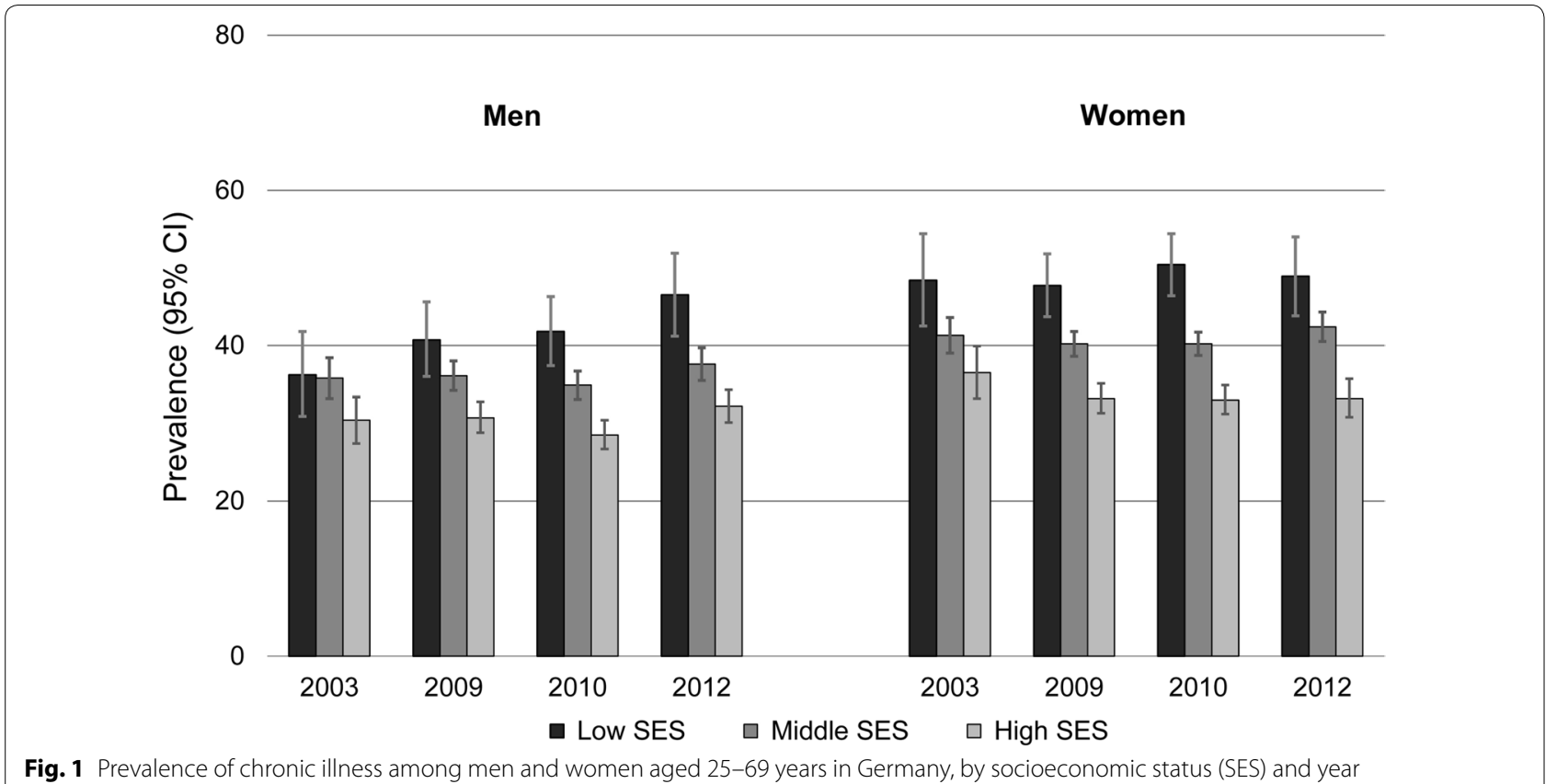

Fig. 1 Prevalence of chronic illness among men and women aged 25-69 years in Germany, by socioeconomic status (SES) and year

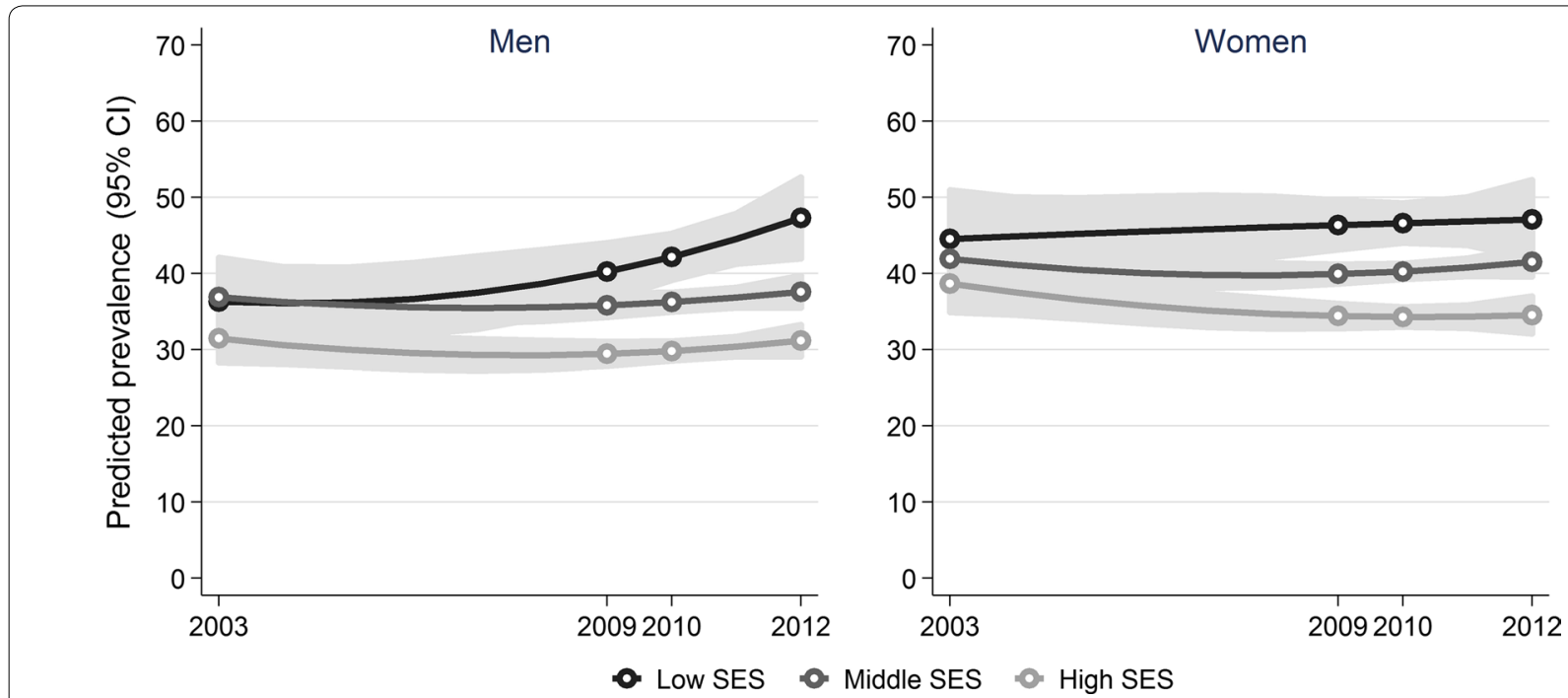

Fig. 2 Predicted age-standardised prevalence of chronic illness among men and women aged 25-69 years in Germany, by socioeconomic status (SES) and year (age-standardised to the revised European Standard Population 2013)

for men revealed a significant increase in socioeconomic inequalities in chronic illness between 2003 and 2012 on both the absolute and relative scales. For women, the results also showed significant increases in absolute and relative inequalities during the study period, although the coefficients tended to fall slightly in the final survey year.

\section{Discussion}

The analysis presented in this paper is the first to investigate post-millennial trends in the extent of socioeconomic inequalities in chronic illness among the general adult population of Germany. The results suggest that both absolute and relative inequalities in chronic illness evolved and widened during the period between 
Table 1 Trends in absolute and relative socioeconomic inequalities in chronic illness among men and women aged 25-69 years in Germany

\begin{tabular}{llllll}
\hline & 2003 & $\mathbf{2 0 0 9}$ & $\mathbf{2 0 1 0}$ & $\mathbf{2 0 1 2}$ & $\boldsymbol{p}$-trend \\
\hline $\begin{array}{l}\text { Men } \\
\text { SII }(95 \% \mathrm{Cl})^{\mathrm{a}}\end{array}$ & $0.06(-0.01$ to 0.13$)$ & $0.11(0.06$ to 0.16$)$ & $0.15(0.10$ to 0.20$)$ & $0.17(0.11$ to 0.22$)$ & 0.013 \\
RII $(95 \% \mathrm{Cl})^{\mathrm{a}}$ & $1.18(0.98$ to 1.41$)$ & $1.31(1.15$ to 1.51$)$ & $1.49(1.30$ to 1.70$)$ & $1.57(1.37$ to 1.80$)$ & 0.013 \\
Women & & & & & \\
SII $(95 \% \mathrm{Cl})^{\mathrm{a}}$ & $0.05(-0.01$ to 0.12$)$ & $0.13(0.09$ to 0.18$)$ & $0.16(0.12$ to 0.20$)$ & $0.14(0.08$ to 0.20$)$ & 0.022 \\
RII $(95 \% \mathrm{Cl})^{\mathrm{a}}$ & $1.14(0.97$ to 1.34$)$ & $1.42(1.27$ to 1.58$)$ & $1.47(1.32$ to 1.64$)$ & $1.40(1.23$ to 1.59$)$ & 0.021 \\
\hline
\end{tabular}

SII slope index of inequality, $R / l$ relative index of inequality, $\mathrm{Cl}$ confidence interval

a Adjusted for age

2003 and 2012. Whereas in men this trend was driven by an increasing prevalence of chronic illness in the low socioeconomic group, the trend in women was predominantly owing to a declining prevalence in the high socioeconomic group.

The health outcome considered in the analysis was chronic illness measured by a single question on selfreported chronic morbidity, as is often used in general health surveys. From the literature, it is known that most widespread chronic conditions, such as diabetes, cardiovascular disease, stroke, chronic back pain, chronic bronchitis or depression, are associated with lower SES [36-41]. An exception, however, are allergies, which are generally found to be associated with higher SES [41, 42]. Against this background, it should be considered that the socioeconomic gradient in conditions such as diabetes, chronic back pain or depression might actually be steeper than estimated in our analysis of chronic illness because allergies, which are generally included in the generic definition of chronic illness, may have attenuated the gradient.

Previous studies on trends in socioeconomic inequalities in chronic illness have shown mixed results. Two Scandinavian studies analysed survey data from the mid-1980s and mid-1990s and found stable or slightly decreasing educational inequalities in (limiting) longstanding illness over time $[17,43]$. Whereas studies on post-millennial trends in socioeconomic inequalities in chronic illness are generally scarce, findings on other health outcomes exist. A large study based on pooled data from 17 European countries showed that between 1990 and 2010, absolute inequalities in self-rated general health were mostly constant whereas relative inequalities increased [13]. Another analysis of large European data sets revealed that absolute and relative inequalities in functional limitations among older people increased between 2002 and 2014 [44]. Inequalities in single widespread diseases, such as diabetes [15], myocardial infarction or stroke $[16,45,46]$, have been found to have remained relatively constant in recent decades.

The results presented in this paper are one more piece of evidence that the socioeconomic gradient in health is persistent over time and suggest that the gradient may even have been exacerbated in Germany since the early 2000s. The findings point to a need for effective strategies to improve health opportunities for socially disadvantaged people. Strategies addressing different policy fields and focussing on material and structural living conditions are especially promising for improving health equity, as people's living conditions are not only directly relevant to health but can also have indirect health effects through influencing behavioural and psychosocial factors $[47,48]$.

\section{Limitations}

There are some study limitations worth noting. The data on SES and chronic illness were based on selfreports, which may be subject to information bias. It has been argued that self-report indicators of chronic morbidity can underestimate the extent of socioeconomic inequalities in ill health because people from lower SES groups may have higher thresholds for perceiving themselves as ill [49-51]. There are, however, empirical data that do not support this hypothesis and suggest that self-reported responses to questions on chronic illness are not essentially biased by SES [52]. Concerning the national representativeness of the survey samples, it must be mentioned that the response rate decreased across the surveys. Nonetheless, the sample bias according to key sociodemographic characteristics increased only slightly between 2003 and 2009 and remained constant thereafter, as discussed in our previous articles based on these data [26, 27]. To minimise the impact of potential selection bias from differential non-response across the surveys, we adjusted year-specifically for non-response using weighting factors (see above). As the weighting procedure considers 
the age, sex, educational level, and regional distribution of the samples, the national representativeness of the samples is limited to these characteristics. The intervals between the health surveys used were not equal, which may have potentially biased the estimation of trends. To prevent such bias, the size of intervals was considered in the statistical models.

\section{Abbreviations}

SES: socioeconomic status; GEDA: German Health Update; SII: slope index of inequality; RIl: relative index of inequality.

\section{Authors' contributions}

$\mathrm{JH}$ reviewed the literature, performed the statistical analysis and drafted the first version of the manuscript. LEK contributed to the statistical analysis. BK and IM contributed to reviewing the literature and drafting the manuscript. $\mathrm{TL}$ supervised the study and reviewed the manuscript critically. All authors contributed to the interpretation of findings. All authors read and approved the final manuscript.

\section{Author details}

${ }^{1}$ Unit of Social Determinants of Health, Department of Epidemiology and Health Monitoring, Robert Koch Institute, General-Pape-Straße 62-66, 12101 Berlin, Germany. ${ }^{2}$ Institute of Medical Sociology, Martin Luther University Halle-Wittenberg, Magdeburger Straße 8, 06112 Halle, Germany.

\section{Acknowledgements}

The authors would like to thank the study participants and all employees of the Robert Koch Institute who helped to conduct the surveys. We also thank Analisa Avila for editing a draft of this manuscript.

\section{Competing interests}

The authors declare that they have no competing interests.

\section{Availability of data and materials}

The datasets are not publicly available because informed consent from study participants did not cover public deposition of data. However, the minimal data set underlying the findings is archived in the 'Health Monitoring' Research Data Centre at the Robert Koch Institute (RKI) and can be accessed on site upon reasonable request. The 'Health Monitoring' Research Data Centre is accredited by the German Data Forum according to uniform and transparent standards. On-site access to the minimal data set is possible at the Secure Data Center of the RKI's 'Health Monitoring' Research Data Centre, which is located at General-Pape-Straße 64 in Berlin, Germany. Requests should be submitted to Dr. Ronny Kuhnert at the Robert Koch Institute, 'Health Monitoring' Research Data Centre, General-Pape-Straße 64, 12101 Berlin, Germany (e-mail: fdz@rki.de).

\section{Consent for publication}

Not applicable.

\section{Ethics approval and consent to participate}

The GEDA study was reviewed and approved by The Federal Commissioner for Data Protection and Freedom of Information in Germany. Verbal informed consent was obtained from all human participants included in the study. Consent was obtained before conducting the telephone interviews. Interviewers informed participants about the purpose and contents of the study and about the voluntary nature of participation. According to the German Federal Data Protection Act (FDPA), consent can be obtained other than in writing when special circumstances warrant any other form [FDPA, section 4a (1)]. In the present study, verbal consent was applicable because the research purpose would have been considerably impaired if consent were obtained in writing [see FDPA, section 4a (2)]. Data were collected exclusively via computerassisted telephone interviews. No physical examination or laboratory testing was performed; no biological samples were collected.

\section{Funding}

The surveys used are part of the Federal Health Monitoring System (FHMS) in Germany, which is administered by the Robert Koch Institute (RKI) on behalf of the German Federal Ministry of Health (BMG). The BMG finances the RKI and contributes substantial funds to the FHMS. The funders had no role in the data collection and analysis, decision to publish, or preparation of the manuscript. All authors are employees of the RKI. None of the authors received specific funding for this work.

\section{Publisher's Note}

Springer Nature remains neutral with regard to jurisdictional claims in published maps and institutional affiliations.

Received: 18 January 2018 Accepted: 20 March 2018

Published online: 27 March 2018

\section{References}

1. Pförtner T-K, Richter M. Getting social: public Health's increasing awareness of the social determinants of health. J Public Health (Springer). 2011;19:1-2.

2. Lampert T, Richter M, Schneider S, Spallek J, Dragano N. Social inequality and health: status and prospects of socio-epidemiological research in Germany. Bundesgesundheitsblatt Gesundheitsforschung Gesundheitsschutz. 2016;59:153-65.

3. Commission on Social Determinants of Health. Closing the gap in a generation: health equity through action on the social determinants of health. Final report of the Commission on Social Determinants of Health. Geneva: World Health Organization; 2008.

4. Cockerham WC, Hamby BW, Oates GR. The social determinants of chronic disease. Am J Prev Med. 2017;52:5-12.

5. Marmot MG, Wilkinson RG. Social determinants of health. Oxford: Oxford University Press; 2006

6. Mackenbach JP, Stirbu I, Roskam A-JR, Schaap MM, Menvielle G, Leinsalu $\mathrm{M}$, et al. Socioeconomic inequalities in health in 22 European countries. N Engl J Med. 2008;358:2468-81.

7. Chetty R, Stepner M, Abraham S, Lin S, Scuderi B, Turner N, et al. The association between income and life expectancy in the United States, 2001-2014. JAMA. 2016:315:1750-66.

8. European Commission. Health inequalities in the EU: final report of a consortium (Consortium lead: Sir Michael Marmot). Brussels: European Commission Directorate-General for Health and Consumers; 2013.

9. Lampert T, Kroll LE. Social differences in mortality and life expectancy. GBE kompakt. 2014;5:1-11.

10. Mackenbach JP, Bos V, Andersen O, Cardano M, Costa G, Harding S, et al Widening socioeconomic inequalities in mortality in six Western European countries. Int J Epidemiol. 2003;32:830-7.

11. Mackenbach JP, Kulhánová I, Artnik B, Bopp M, Borrell C, Clemens T, et al. Changes in mortality inequalities over two decades: register based study of European countries. BMJ. 2016;353:i1732.

12. Strand BH, Groholt EK, Steingrimsdottir OA, Blakely T, Graff-Iversen $\mathrm{S}$, Naess $\mathrm{O}$. Educational inequalities in mortality over four decades in Norway: prospective study of middle aged men and women followed for cause specific mortality, 1960-2000. BMJ. 2010;340:c654.

13. Hu Y, van Lenthe FJ, Borsboom GJ, Looman CW, Bopp M, Burstrom B, et al. Trends in socioeconomic inequalities in self-assessed health in 17 European countries between 1990 and 2010. J Epidemiol Community Health. 2016;70:644-52.

14. Kunst AE, Bos V, Lahelma E, Bartley M, Lissau I, Regidor E, et al. Trends in socioeconomic inequalities in self-assessed health in 10 European countries. Int J Epidemiol. 2005;34:295-305.

15. Menke A, Casagrande S, Geiss L, Cowie CC. Prevalence of and trends in diabetes among adults in the United States, 1988-2012. JAMA. 2015;314:1021-9.

16. Lammintausta A, Immonen-Raiha P, Airaksinen JK, Torppa J, Harald K, Ketonen $\mathrm{M}$, et al. Socioeconomic inequalities in the morbidity and mortality of acute coronary events in Finland: 1988-2002. Ann Epidemiol. 2012;22:87-93 
17. Lahelma E, Kivela K, Roos E, Tuominen T, Dahl E, Diderichsen F, et al. Analysing changes of health inequalities in the Nordic welfare states. Soc Sci Med. 2002;55:609-25.

18. Kroll LE, Lampert T. Changing health inequalities in Germany from 1994 to 2008 between employed and unemployed adults. Int J Public Health. 2011;56:329-39.

19. Moor I, Richter M, Ravens-Sieberer U, Ottova-Jordan V, Elgar FJ, Pförtner TK. Trends in social inequalities in adolescent health complaints from 1994 to 2010 in Europe, North America and Israel: the HBSC study. Eur J Public Health. 2015;25:57-60.

20. Nolte E, McKee M. Changing health inequalities in east and west Germany since unification. Soc Sci Med. 2004;58:119-36.

21. Kurth BM, Ziese T, Tiemann F. Health monitoring on a federal level: approaches and perspectives. Bundesgesundheitsblatt Gesundheitsforschung Gesundheitsschutz. 2005:48:261-72.

22. Kurth $\mathrm{BM}$, Lange $\mathrm{C}$, Kamtsiuris $\mathrm{P}$, Hölling $\mathrm{H}$. Health monitoring at the Robert Koch Institute: status and perspectives. Bundesgesundheitsblatt Gesundheitsforschung Gesundheitsschutz. 2009;52:557-70.

23. Lange C, Jentsch F, Allen J, Hoebel J, Kratz AL, von der Lippe E, et al. Data Resource Profile: German Health Update (GEDA) - the health interview survey for adults in Germany. Int J Epidemiol. 2015;44:442-50.

24. Kurth BM, Kamtsiuris $P$, Hölling $H$, Schlaud $M$, Dölle R, Ellert $U$, et al. The challenge of comprehensively mapping children's health in a nationwide health survey: design of the German KiGGS-Study. BMC Public Health. 2008:8:196.

25. Scheidt-Nave C, Kamtsiuris P, Gößwald A, Hölling H, Lange M, Busch MA et al. German health interview and examination survey for adults (DEGS): design, objectives and implementation of the first data collection wave. BMC Public Health. 2012;12:730.

26. Hoebel J, Kuntz B, Kroll LE, Finger JD, Zeiher J, Lange C, et al. Trends in absolute and relative educational inequalities in adult smoking since the early 2000s: the case of Germany. Nicotine Tob Res. 2018;20:295-302.

27. Hoebel J, Finger JD, Kuntz B, Kroll LE, Manz K, Lange C, et al. Changing educational inequalities in sporting inactivity among adults in Germany: a trend study from 2003 to 2012. BMC Public Health. 2017;17:547.

28. Kohler M, Rieck A, Borch S. Methode und Design des telefonischen Gesundheitssurveys 2003 [Method and design of the Telephone Health Survey 2003]. Bundesgesundheitsbl. 2005;48:1224-30.

29. Lampert T, Kroll LE, Müters S, Stolzenberg H. Measurement of socioeconomic status in the German health interview and examination survey for adults (DEGS1). Bundesgesundheitsblatt Gesundheitsforschung Gesundheitsschutz. 2013:56:631-6.

30. Lampert T, Kroll LE, Müters S, Stolzenberg H. Measurement of the socioeconomic status within the German health update 2009 (GEDA) Bundesgesundheitsblatt Gesundheitsforschung Gesundheitsschutz. 2013;56:131-43.

31. Graubard BI, Korn EL. Predictive margins with survey data. Biometrics. 1999;55:652-9.

32. Harper S, Lynch J. Measuring health inequalities. In: Oakes JM, Kaufman JS, editors. Methods in social epidemiology. San Francisco: Jossey-Bass; 2006. p. 134-68.

33. Mackenbach JP, Kunst AE. Measuring the magnitude of socio-economic inequalities in health: an overview of available measures illustrated with two examples from Europe. Soc Sci Med. 1997;44:757-71.

34. Wagstaff $A$, Paci $P$, van Doorslaer $E$. On the measurement of inequalities in health. Soc Sci Med. 1991;33:545-57.
35. Harper S, King NB, Young ME. Impact of selective evidence presentation on judgments of health inequality trends: an experimental study. PLoS ONE. 2013:8:e63362.

36. Agardh E, Allebeck P, Hallqvist J, Moradi T, Sidorchuk A. Type 2 diabetes incidence and socio-economic position: a systematic review and metaanalysis. Int J Epidemiol. 2011;40:804-18.

37. Galobardes B, Smith GD, Lynch JW. Systematic review of the influence of childhood socioeconomic circumstances on risk for cardiovascular disease in adulthood. Ann Epidemiol. 2006:16:91-104.

38. Ellison-Loschmann L, Sunyer J, Plana E, Pearce N, Zock JP, Jarvis D, et al. Socioeconomic status, asthma and chronic bronchitis in a large community-based study. Eur Respir J. 2007;29:897-905.

39. Kuntz B, Hoebel J, Fuchs J, Neuhauser H, Lampert T. Social inequalities in the prevalence of chronic back pain among adults in Germany. Bundesgesundheitsblatt Gesundheitsforschung Gesundheitsschutz. 2017:60:783-91.

40. Lorant V, Deliège D, Eaton W, Robert A, Philippot P, Ansseau M. Socioeconomic inequalities in depression: a meta-analysis. Am J Epidemiol. 2003;157:98-112.

41. Dalstra JA, Kunst AE, Borrell C, Breeze E, Cambois E, Costa G, et al. Socioeconomic differences in the prevalence of common chronic diseases: an overview of eight European countries. Int J Epidemiol. 2005;34:316-26.

42. McNamara $\mathrm{CL}$, Balaj M, Thomson KH, Eikemo TA, Solheim EF, Bambra C. The socioeconomic distribution of non-communicable diseases in Europe: findings from the European Social Survey (2014) special module on the social determinants of health. Eur J Public Health. 2017;27:22-6.

43. Krokstad S, Kunst A, Westin S. Trends in health inequalities by educational level in a Norwegian total population study. J Epidemiol Community Health. 2002;56:375-80.

44. von dem Knesebeck O, Vonneilich N, Ludecke D. Income and functional limitations among the aged in Europe: a trend analysis in 16 countries. J Epidemiol Community Health. 2017;71:584-91.

45. Igland J, Vollset SE, Nygard OK, Sulo G, Ebbing M, Tell GS. Educational inequalities in acute myocardial infarction incidence in Norway: a nationwide cohort study. PLOS ONE. 2014;9:e106898.

46. Malki N, Koupil I, Eloranta S, Weibull CE, Tiikkaja S, Ingelsson E, et al. Temporal trends in incidence of myocardial infarction and ischemic stroke by socioeconomic position in Sweden 1987-2010. PLoS ONE. 2014;9:e105279.

47. World Health Organization. Health in all policies (HiAP): framework for country action. Geneva: WHO; 2014

48. Moor I, Spallek J, Richter M. Explaining socioeconomic inequalities in selfrated health: a systematic review of the relative contribution of material, psychosocial and behavioural factors. J Epidemiol Community Health. 2017;71:565-75.

49. Koos EL. The health of Regionville: what the people thought and did about it. New York: Columbia University Press; 1954.

50. Blaxter M. Self-definition of health status and consulting rates in primary care. Q J Soc Aff. 1985;1:131-71.

51. Mackenbach JP, Looman CW, van der Meer JB. Differences in the misreporting of chronic conditions, by level of education: the effect on inequalities in prevalence rates. Am J Public Health. 1996;86:706-11.

52. Macintyre S, Der G, Norrie J. Are there socioeconomic differences in responses to a commonly used self report measure of chronic illness? Int J Epidemiol. 2005;34:1284-90. 